\title{
A Comparison of Methods for Increasing Retention of Complete Veneer Crowns
}

\author{
Roger Martin Weed
}

\begin{abstract}
Aim: To determine if boxes or grooves were effective in enhancing the retention of full veneer crowns.
\end{abstract}

\begin{abstract}
Materials and methods: Ten full veneer crown preparations were machined out of brass with 10 different configurations. They consisted of a plain short preparation, a plain long preparation and preparations with 1 to 4 boxes or 1 to 4 grooves. Ten gold castings were fabricated for each preparation and the cemented. An Instron* was used to remove the castings with the force required recorded in Newtons.
\end{abstract}

Results: Statistical differences were found in retention between various configurations with boxes being universally more retentive than grooves or the plain crowns.

Conclusion: All the box configurations significantly enhanced retention. Therefore, one box alone would provide the enhanced retention needed for a full veneer crown without the need to create additional retention features.

Keywords: Box, Crown, Groove, Retention.

How to cite this article: Weed RM. A Comparison of Methods for Increasing Retention of Complete Veneer Crowns. Int J Experiment Dent Sci 2015;4(2):95-98.

Source of support: Nil

Conflict of interest: None

\section{INTRODUCTION}

In today's world of bonded restorations, resistance and retention features are often overlooked in the preparation design for full veneer crowns. Historically, those features were considered critical in the long-term success of cast restorations. It is a dental axiom that adequate retention/ resistance form must be established when preparing teeth for full veneer crowns. To achieve this, there are

Associate Professor

Department of Comprehensive Dentistry, University of Texas Health Science Center School of Dentistry, Texas United States

Corresponding Author: Roger Martin Weed, Associate Professor, Department of Comprehensive Dentistry, University of Texas Health Science Center School of Dentistry, Texas United States, Phone: 2105673442, e-mail:weed@uthscsa.edu certain critical factors, such as taper, length, and retentive surface area that must be considered. ${ }^{1}$ For the usual clinical crown, the operator has considerable latitude in how much he can vary some of these factors with altering taper/convergence being the most common. Jorgensen ${ }^{2}$ in 1955 was among the first to determine experimentally that as taper increased retention decreased. In consideration of this phenomenon, a number of authors have recommended what they consider to be ideal tapers. Johnston's text ${ }^{3}$ recommends a taper of 3 to $5^{\circ}$.

Tylman ${ }^{4}$ has recommended and ideal taper of 2 to $5^{\circ}$, Rosenestiel ${ }^{5}$ has also recommended a 3 to $5^{\circ}$ taper while Shillingburg ${ }^{6}$ text relates that $16^{\circ}$ was acceptable in certain teeth. Weed et $\mathrm{al}^{7}$ however, found that dental students treating clinical patients produced an average of $22.8^{\circ}$ of taper on posterior teeth. As can be determined by simple geometry, for a crown of the same length, as taper decreases the surface area decrease and, therefore, so does the retention. Therefore, when dealing with a short clinical crown, especially when crown lengthening is not indicated, additional methods of increasing retention may be considered. Some clinicians advocate the use of auxiliary retentive forms, such as boxes and grooves to increase the retentive characteristics of those short preparations. ${ }^{8,9}$ Reisbick ${ }^{10}$ reported that grooves did not aid in the retention of full crowns and Rosenestie ${ }^{11}$ recommended flared boxes or ' $U$ ' shaped grooves.

This short study was performed to compare the retentive relationships of boxes and grooves in contrast to crowns without additional retention features. There were two objectives to this study:

1. Comparing boxes and grooves and their effect on increasing retention.

2. The optimal number of boxes and or grooves to increase retention.

\section{MATERIALS AND METHODS}

Ten simulated full veneer crown preparations were machined out of brass, each with a different simulated crown configuration. They consisted of a short plain short crown $4.3 \mathrm{~mm}$ in length at the cups tip and $3.8 \mathrm{~mm}$ at the simulated marginal ridge and a long plain crown $7.00 \mathrm{~mm}$ in length at the cusp tip and $5.2 \mathrm{~mm}$ at the

* Illinois tool works INC 


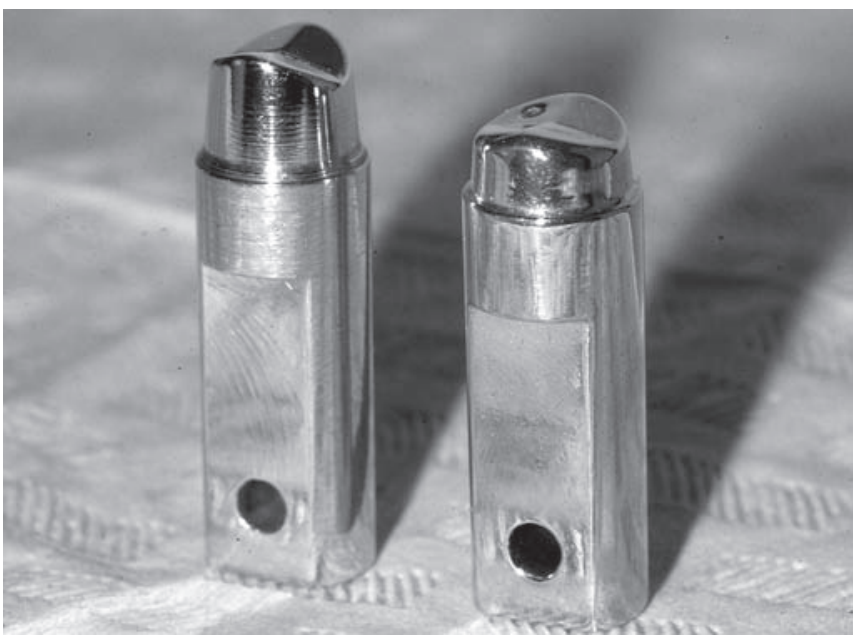

Fig. 1: On left plain $7 \mathrm{~mm}$ preparation, on the right $4.3 \mathrm{~mm}$ preparation

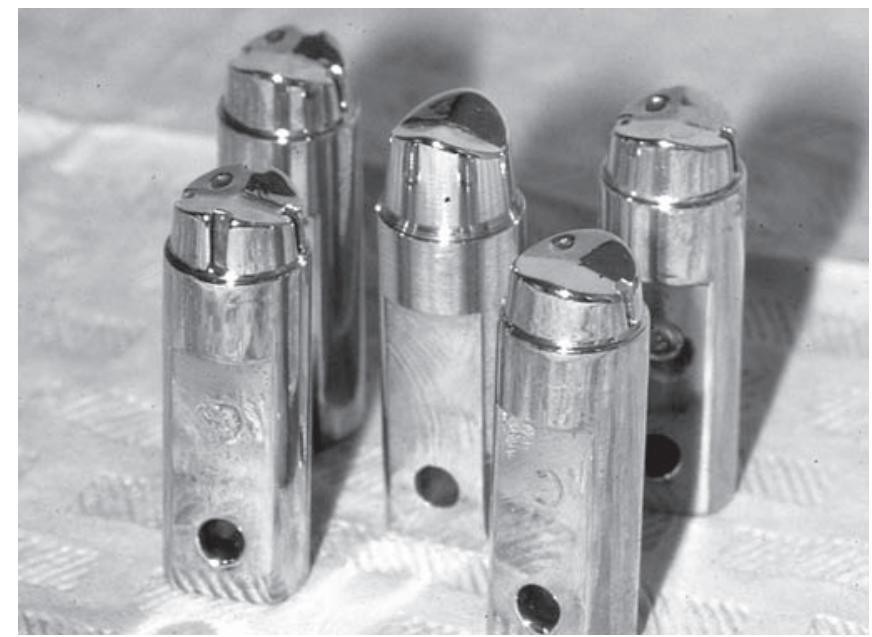

Fig. 3: Crown preparations with boxes: left rear-3 boxes, left front -4 boxes, center $-7 \mathrm{~mm}$ long plain crown, right rear -2 boxes and right front -1 box

simulated marginal ridge (Fig. 1). The eight other preparations consisted of four short crowns with 1, 2, 3, and 4 grooves (Fig. 2) and four short crowns with 1, 2, 3, and 4 (Fig. 3) boxes respectively, which were also $4.3 \mathrm{~mm}$ in length at the cups tip and $3.8 \mathrm{~mm}$ at the simulated marginal ridge. The convergence angle was $10.0^{\circ}$ with a $0.5 \mathrm{~mm}$ chamfer margin. The boxes and grooves were all prepared with a $2^{\circ}$ taper of the walls. The boxes and grooves on the mesial and distal surfaces were $2.5 \mathrm{~mm}$ long and those on the facial and lingual surfaces were 3.8 $\mathrm{mm}$ long. All boxes were $1.0 \mathrm{~m}$ wide and $1.0 \mathrm{~mm}$ deep at their base and had sharp line angles. The grooves were shaped like half cones with rounded ends and with the wider portion toward the occlusal surface. The width of the base of the groove was $1.5 \mathrm{~m}$ and was $0.75 \mathrm{~mm}$ deep.

The boxes and grooves were placed in the same position on their respective preparations, the first one on the mesial the second on the distal the third on the

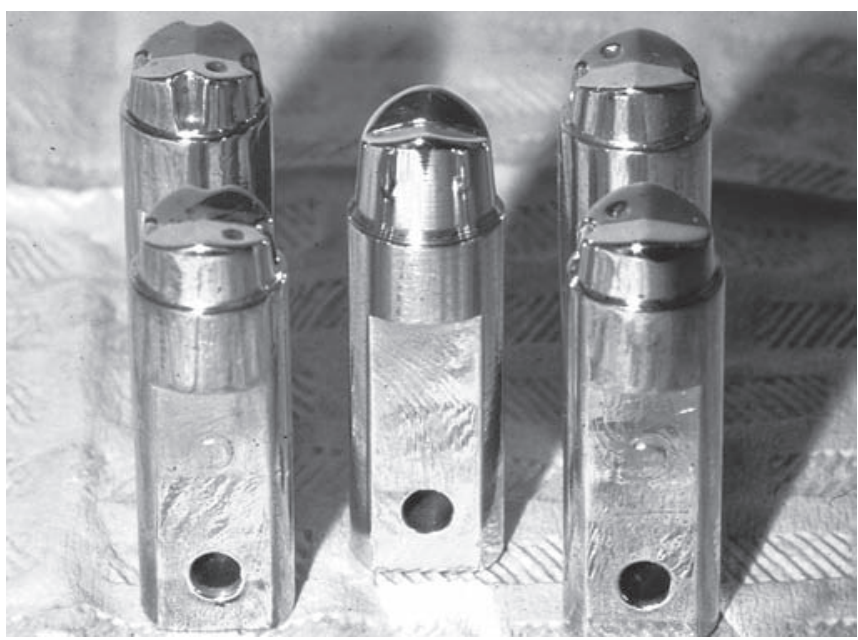

Fig. 2: Crown preparations with grooves: left rear-4 grooves, left front-3 grooves, center-7 $\mathrm{mm}$ long plain crown, right rear-2 grooves and right front -1 groove

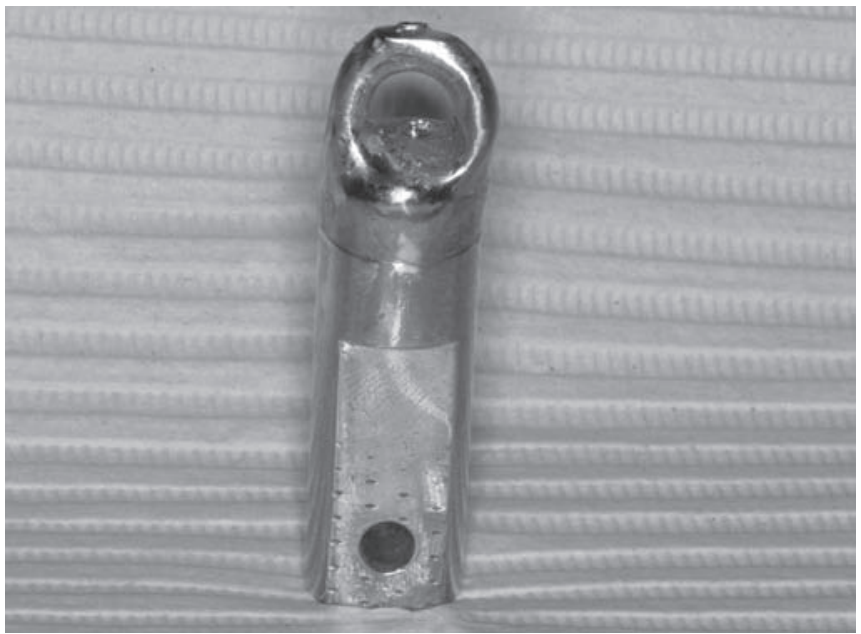

Fig. 4: Cemented and vented casting prepared for testing

facial and the forth on the lingual. Wax patterns were fabricated directly on the preparations and sprued with a ' $U$ ' shaped loop to facilitate in the casting removal for testing. The patterns were invested, burnt-out, and then cast in type three gold using conventional materials and methods. The castings were reseated on the brass preparations and the margins examined (Fig. 4). Any casting with a defect that would prevent its seating or any margin open greater than 50 microns was remade. All castings were vented on the occlusal surface prior to cementation to improve the marginal fit. ${ }^{12}$ The castings were cemented with zinc phosphate cement and allowed to set 24 hours before testing. An Instron (Illinois Tool Works Inc) universal testing machine (Fig. 5) was used to remove the castings from their preparations and the tensile forces involved recorded in Newtons. Ten new acceptable castings for each preparation were made and tested for a total of 100 castings. 


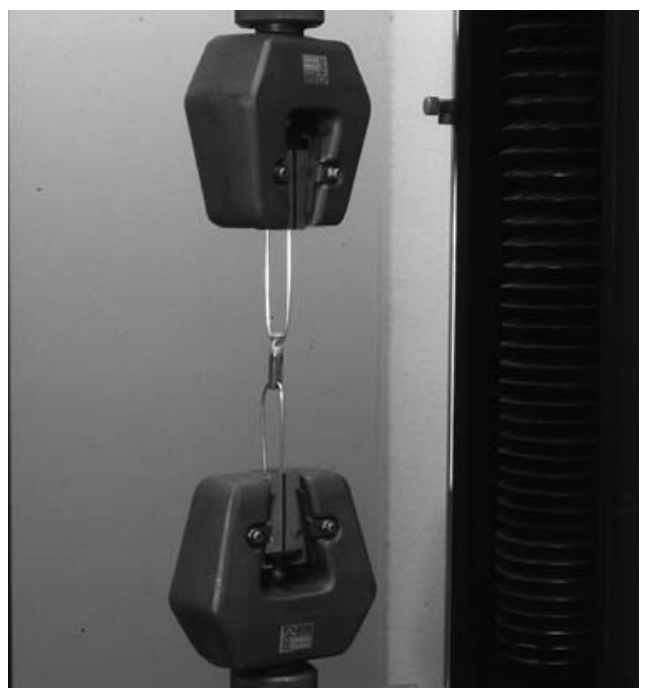

Fig. 5: Casting being tensile tested on universal testing machine

\section{RESULTS}

The ten groups of data were analyzed by a one way analysis of variance (ANOVA) and a significant F-value was obtained, $p=0.0001$ (Table 1). A Duncan's test was used to demonstrate where the differences existed (Table 2).

\section{DISCUSSION}

Grooves as a group were significantly inferior to boxes for increasing retention. The one, two, and three groove preparations demonstrated no improvement in retention when compared to the plain short crown. Only the four groove preparation had a significant increase of retention. All box preparations were superior to all other preparations types evaluated. When evaluated as a separate group, the number of boxes were of no

Table 1: Analysis of variance

\begin{tabular}{|c|c|c|c|c|c|}
\hline Groups & \multicolumn{2}{|c|}{ Number of subjects } & Mean deviation & \multicolumn{2}{|c|}{ Standard deviation } \\
\hline 1 & \multicolumn{2}{|c|}{10} & 586 & \multicolumn{2}{|c|}{135.12} \\
\hline 2 & \multicolumn{2}{|l|}{10} & 517 & \multicolumn{2}{|c|}{165.7} \\
\hline 3 & \multicolumn{2}{|l|}{10} & 548 & \multicolumn{2}{|c|}{153.97} \\
\hline 4 & \multicolumn{2}{|l|}{10} & 633 & \multicolumn{2}{|c|}{93.5} \\
\hline 5 & \multicolumn{2}{|l|}{10} & 358 & \multicolumn{2}{|c|}{131.72} \\
\hline 6 & \multicolumn{2}{|l|}{10} & 310 & \multicolumn{2}{|c|}{107.7} \\
\hline 7 & \multicolumn{2}{|l|}{10} & 304 & \multicolumn{2}{|c|}{92.08} \\
\hline 8 & \multicolumn{2}{|l|}{10} & 336 & \multicolumn{2}{|c|}{119.28} \\
\hline 9 & \multicolumn{2}{|l|}{10} & 487 & \multicolumn{2}{|c|}{7836} \\
\hline \multirow[t]{2}{*}{10} & \multicolumn{2}{|l|}{10} & 457 & \multicolumn{2}{|c|}{59.82} \\
\hline & SS & $d f$ & MS & $f$ & $p$ \\
\hline Between & $1,297,424.000$ & 9 & $144,158.222$ & \multirow{2}{*}{\multicolumn{2}{|c|}{10.328}} \\
\hline Within & $1,256,176.808$ & 90 & $13,957.520$ & & \\
\hline Total & $2,553,600.808$ & 99 & & & \\
\hline 1 Box = group 1 & & $4 \mathrm{Box}=\mathrm{g}$ & & \multicolumn{2}{|c|}{3 Groove = group 8} \\
\hline 2 Box = group 2 & & 4.3 Crow & & \multicolumn{2}{|c|}{4 Groove = group 9} \\
\hline \multirow[t]{2}{*}{3 Box = group 3} & \multicolumn{3}{|c|}{1 Groove = group 6} & \multicolumn{2}{|c|}{ 7.0 Crown = group 10} \\
\hline & & 2 Groove & & & \\
\hline
\end{tabular}

Table 2: Duncan's multiple range test

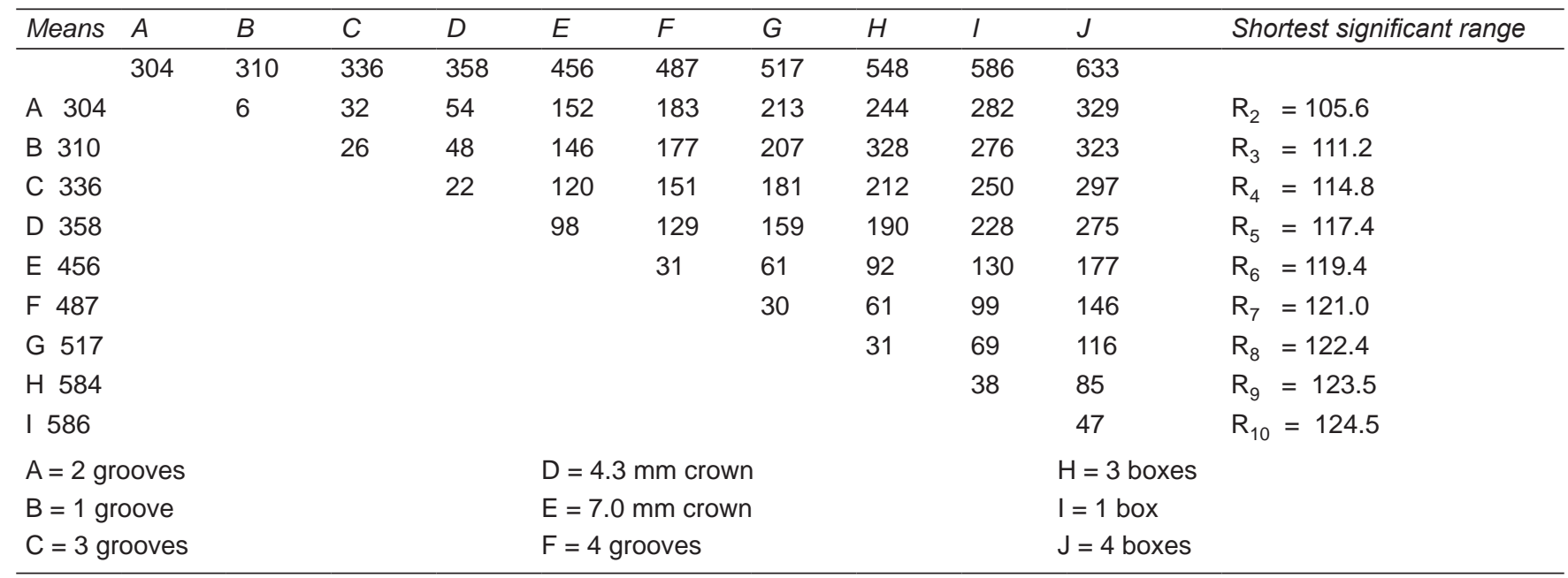


statistical difference for increasing retention. Therefore, one well-prepared box was statistically as retentive as four well-placed boxes. Based on the results of this study, the use of grooves is not recommended for increasing the retention of short clinical crowns. Boxes are the auxiliary retentive feature recommended because of the demonstrated superiority to both the plain and grooved preparations. The optimum number of boxes to be used is not recommended because no statistical difference could be determined.

\section{CONCLUSION}

The main observation that can be drawn from this study is that preparations types may be rank ordered as:

- Least effective: 1 to 3 grooves and the short crown

- Moderate effect: 4 grooves and the long crown

- Most effective: all boxes

Overall, it was observed that: (1) long crowns are more retentive than short crowns, (2) boxes are superior to grooves for increasing retention and that (3) at least one well prepared and placed box will significantly increase the retention of a short clinical crown. The results of the present study are intriguing and should be interpreted from a clinical perspective. ${ }^{13}$

\section{ACKNOWLEDGMENT}

In recognition of Richard N Buchanan DMD who was my mentor and inspiration for this project.

\section{REFERENCES}

1. Sharma A, Rahul GR, Poduval ST, Shetty K. Short clinical crowns-treatment considerations and techniques. J Clin Exper Dent 2012;4(4):e230-e236.

2. Jorgensen KD. The relationship between retention and convergence angle in cemented veneer crowns. Acta Odontol Scand 1955 Jun;13(1):35-40.

3. Dykema RF, Goodacre CA, Phillips RW. Johnston's Modern Practice in Fixed Prosthodontics. 4th ed. Philadelphia. WB Saunders Co; 1986. p. 41.

4. Malone WFP, Koth DL. Tylman's Theory and Practice of Fixed Prosthodontics. 8th ed. St Louis: Ishiyahu Euro-America Inc 1989. p. 156.

5. Rosenestiel SF, Land MF, Fujimoto J. Contemporary Fixed Prosthodontics. 3rd ed. St Louis, MO, Mosby; 2001. p. 24.

6. Shillingburg HT, Hobo S, Whitsett LD, Jacobi R, Brackett SE. Fundamental of Fixed Prosthodontics. 3rd ed. Carol Stream IL: Quntessence Publishing Co Inc; 1997. p. 120.

7. Weed RM, Suddic, RP, Kleffner JH. Taper of clinical and typdont crowns prepared by dental students. J Dent Res 1984;63:286.

8. Blair FM, Wassell RW, Steele JG. Crowns and other extracoronal restorations: preparations for full veneer crowns. Br Dent J 2002 May;192:561-571.

9. Dykema RF, Goodacre CA, Phillips RW. Johnston's Modern Practice in Fixed Prosthodontics. 4th ed. Philadelphia: WB Saunders Co; 1986. p. 40.

10. Reisbick MH, Shillingburg HT Jr. Effects of preparation geometry on retention and resistance of cast gold restorations. J Calif Dent Assoc 1975 Apr;3(4):51-59.

11. Rosenestiel SF, Land MF, Fujimoto J. Contemporary fixed prosthodontics. 3rd ed. St Louis MO: Mosby; 2001. p. 189.

12. Small B. The Vented crown: a pictorial case report. Operative Dentistry 2013 Mar-Apr;38(2):113-118.

13. Saini R. A prospective experimental comparative study on the clinical effects of calculus dissolution based oral rinse in gingivitis patients. Int J Experiment Dent Sci 2015;4(1):33-39. 